\title{
Brandy Melville's Global Marketing Strategies in China
}

\author{
Xinrui $\mathrm{Wu}^{1 *}$, Yuhan $\mathrm{Zha}^{2}$, Cathy $\mathrm{Li}^{3}$ \\ ${ }^{1}$ York School, Monterey, California, 93940 \\ ${ }^{2}$ Beijing Normal University-Hongkong Baptist University United International College \\ ${ }^{3}$ Collegiate School, Richmond, VA, 23229 \\ * Corresponding author. Email: xinruiwu0301@gmail.com
}

\begin{abstract}
In September 2019, Brandy Melville, an Italian company within the clothing industry, opened its first and currently the only store in Shanghai, China [4]. It soon gained popularity among young people, especially females. Many people rushed to the store to buy clothes, bags, and hairpins. Compared to similar brands like Forever 21 and Hollister, Brandy Melville (abbreviated as BM) succeeds in building its "Californian girl" and "American sweetness" profile through various means, including promoting an "ideal body type," controlling scarcity of its products, and employing celebrity charm. These strategies lend success to the brand in China, but they also led to negative consequences for both the firm and society.

Hence, this report aims to examine three strategies that Brandy Melville employed when entering the Chinese market and the positive and negative effects these strategies bring to both the brand and customers. To achieve this purpose, the report incorporates secondary research sources to provide context about marketing strategies, including Brandy Melville specifically but also utilizes primary data through original analysis of Brandy Melville's social media account.
\end{abstract}

Keywords: Brandy Melville, body shaming, scarce supply, celebrity charm

\section{BRANDY MELVILLE'S STRATEGY'S OF PROPAGATING THE NOTION OF "IDEALIZED BODY TYPE"}

As the basic marketing strategy of Brandy Melville, advocating "the ideal body type," not only creates a sales highlight for Brandy Melville but also generates some social criticism. All clothes of BM only have one size, which corresponds to regular "xs" or "s" size [17]. So Brandy Melville restricts the standard body type to the small one size and defines the "one size" as the ideal body type.

\subsection{The Success of "Ideal Body Type"}

"One size" clothes greatly help BM stand out from other brands that have a variety of sizes for customers to choose from. Moreover, it meets the demand of its target consumers by satisfying their vanity. Most of Brandy Melville's consumers - young women aging from 17 to 25 - feel satisfied when they find they can fit in the "one size" of BM. Some of them still enjoy buying BM although they know the "one size" policy is irrational [16].

According to Lei Zhang in 2018, nowadays in China, more and more people associate beauty with being underweight. Among Chinese young women, beauty is defined as "creamy white skin, big wide eyes, and stickthin figures" [6]. As a result, Brandy Melville's ideal body concept matches the opinion of the Chinese mainstream. When Chinese young women put on shrunken BM clothes, they think they are thin and thus, more beautiful and successful than others. Using the "one size" policy, BM has successfully connected thinness to beauty and success, which caters to Chinese culture. This is part of the reason why BM receives extreme popularity when it enters the Chinese market.

\subsection{Controversy from "Ideal Body Type"}

However, the ideal body type that BM builds also causes controversy and criticism from customers and the public. According to Brady in 2020, although facing criticism for lack of body and racial diversity for years, BM still insists on its "one size" policy and neglects other 
customers' demands. Many customers feel frustrated when they can't fit in BM's clothes and experience dissatisfaction about the brand only providing one size for it, thus causing insecurities and underconfidence among the consumers [12]. While certain groups of people are satisfied with fitting in BM's one size clothes, others, especially teenage girls at such a sensitive life stage, may feel not as perfect as the portrayedBM girls. So, BM's single size choice limits beauty diversity and harms many girls' psychological mindsets.

The controversy that Brandy Melville faces is not only towards the diversity of demands that Brandy Melville cannot meet but also towards the bad influence that its propaganda concept brings to society. To form a visual impact of perceiving thin as beautiful, Brandy Melville takes "fit in one size" as its marketing strategy: it prefers slim and bony models in social media advertising and staff hiring. As a popular brand among teenagers, especially among young girls, such advertising has a wrong guiding effect on their understanding of beauty. According to a study of Italian teenagers, " media - the ideal internalization predicted the self objectification, which in turn predicted body shame and anxiety, and subsequently disordered eating behaviors " [13]. When the media defines the standard of beauty, conformity drives people to pursue this standard of "perfection". BM takes thin as beauty, and if the pursuit of thinness amongst the public goes to the extreme, affecting the overall public health, such as unhealthy diets, anorexia, and such problematic issues.

In addition to creating unhealthy conditions, the promotion may also increase social pressure on women. When society defines female beauty as "ideal thinness" because of the publicity of a brand, it is a kind of social discrimination against women. And women themselves also will be unconsciously guided by fashion propaganda and begin to examine and doubt themselves. The public opinion and inferiority of society force women to conform to the advertised standard of beauty, which may lead to an increase in pressure in women's life.

\section{BRANDY MELVILLE'S MARETING STRATEGY OF UTILIZING SCARE SUPPLY AND PRODUCT POPULARITY}

Other than promoting an "ideal body type," the manipulation of scarcity in product supply expanded its demand group conspicuously. This marketing strategy, also called rationing strategy, made Brandy Melville stand out from its counterparts - brands targeting young people, chiefly from age 17 to 25 . While Brandy's unique style of clothing, for instance, its famous chequer patterns (see figure1), lends competitiveness to the brand, the contribution of its quantity supplied also cannot be ignored.

\subsection{Benefits from Controlling Scarcity}

Based on conventional wisdom, a small quantity supplied means less profit. However, Brandy Melville made a genuine move. Scarcity is defined as "a real or perceived threat to the consumers' ability to meet his or her needs and desires due to a lack of, or a lack access to goods, services, or resources," and it directly influences how consumers process information and make decisions on a psychological level [7]. One of those triggers that affect consumers' decisions is quality. When first entering a market, a lot of preliminary work is needed for a brand that seeks success. In Rationing Capacity in Advance Selling to Signal Quality, the product selling period can be divided into two parts - advance and spot [20]. In advance, the time when the product is not sold yet, the quality is unknown to the consumers. Consumers can get to the product in spot. During advance, some firms make their products hard to get to indicate the high quality of the goods, thus successfully promoting their product [18]. When Brandy Melville just established their first branch in China, the quality of the goods was unknown to local consumers. But brands set forth the strategy of making the goods scarce, implying that the clothes have higher quality. High quality brings popularity and higher demand. Brandy Melville created a bandwagoning illusion to consumers that their products are well-made and prominent, and the consumer who does not get one would feel outmoded. Indeed, when the quantity supplied is lowered, profit is also lowered in the short-term, but for businesses like Brandy Melville that seek long-term success, this strategy is indispensable.

Other than the norm that scarcity is directly proportional to the quality, there is also a proverb saying that "the grass is always greener on the other side," meaning things that people do not have become more appealing than they actually are. A study suggests that residents from Munich perceive their neighbors' lives in Venice better than their own [5]. A similar situation is present within the clothing industry. When consumers are attracted to clothes from Brandy Melville but it is out of stock, they are likely to become more obsessed with it. They can see other individuals wearing similar clothing on the street, scroll through celebrities' pretty selfies in these clothes, or simply imagining how gorgeous they would look wearing this product, and then become even more desperate in getting it.

Brandy Melville is mastering the trick of scarcity. On its social media page, consumers leave comments about how they wish the brand can put more of the products on the shelf. Under an official Xiaohongshu post that describes new products, a fan asked for the replenishment of a cara skirt, while another asked for a hoodie, claiming that she has been waiting for half a year. Similar requests are present under almost all posts. This shows how the marketing strategy of controlling product scarcity gave rise to consumers' passion for the brand. 


\subsection{Negative Consequences From Controlling Scarcity}

The rationing strategy laid the foundation for Brandy Melville's success in China, but it also negatively affects the brand's revenue. When demand exceeds supply by an immense amount, and as a brand becomes well-known, counterfeit products emerge in the market. Although counterfeiting is a common problem for all popular clothing brands, Brandy Melville could have avoided this situation. Unlike luxury brands, Brandy Melville uses raw materials that are not expensive, which allows counterfeiters to precisely copy their clothes. While counterfeiting is pervasive in China, the existence of these goods is particularly devastating to the original brands in the Chinese market [11]. For instance, when the Italian luxury brand Valentino Garavani decided to march into the Chinese market, more than 200 counterfeit brands were discovered, which completely blocked Valentino's profit, making it losing possible revenues that it would have gained in China [9]. Similarly, for Brandy Melville, on Alibaba - the Chinese biggest online retailing platform - a lot of similar items appeared (see figure 2). When people can conveniently get a similar product at a lower price, there is no reason to wait for six months for a replenishment. The emergence of a significant number of counterfeit products led Brandy Melville to lose a considerable amount of demand.

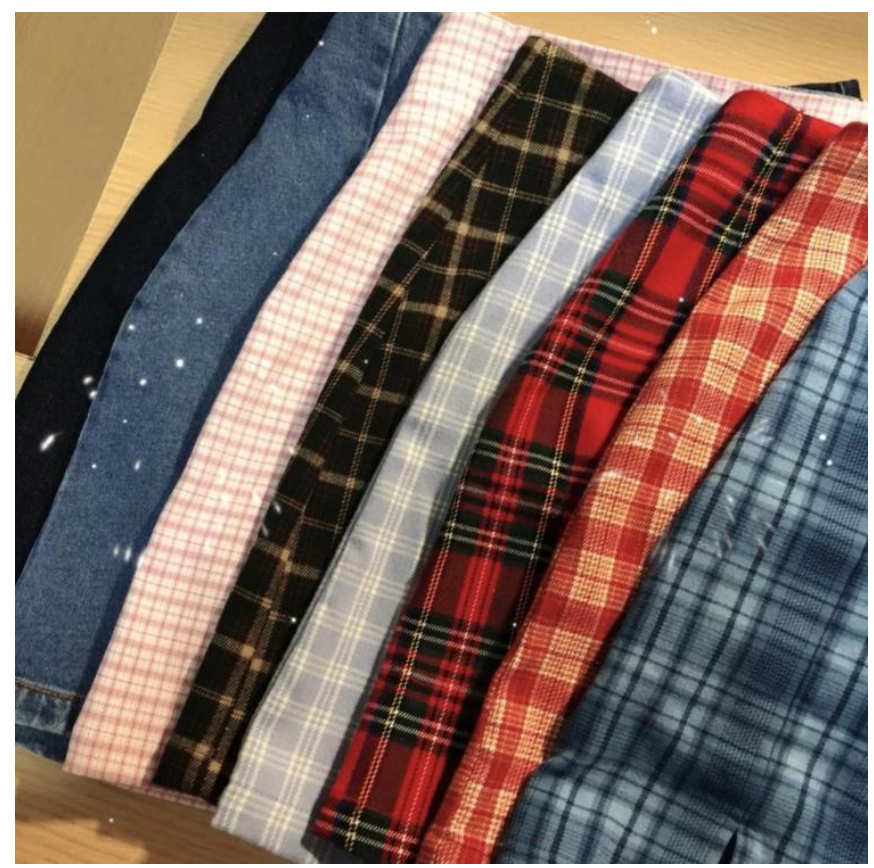

Figure 1 Chequer Pattern 

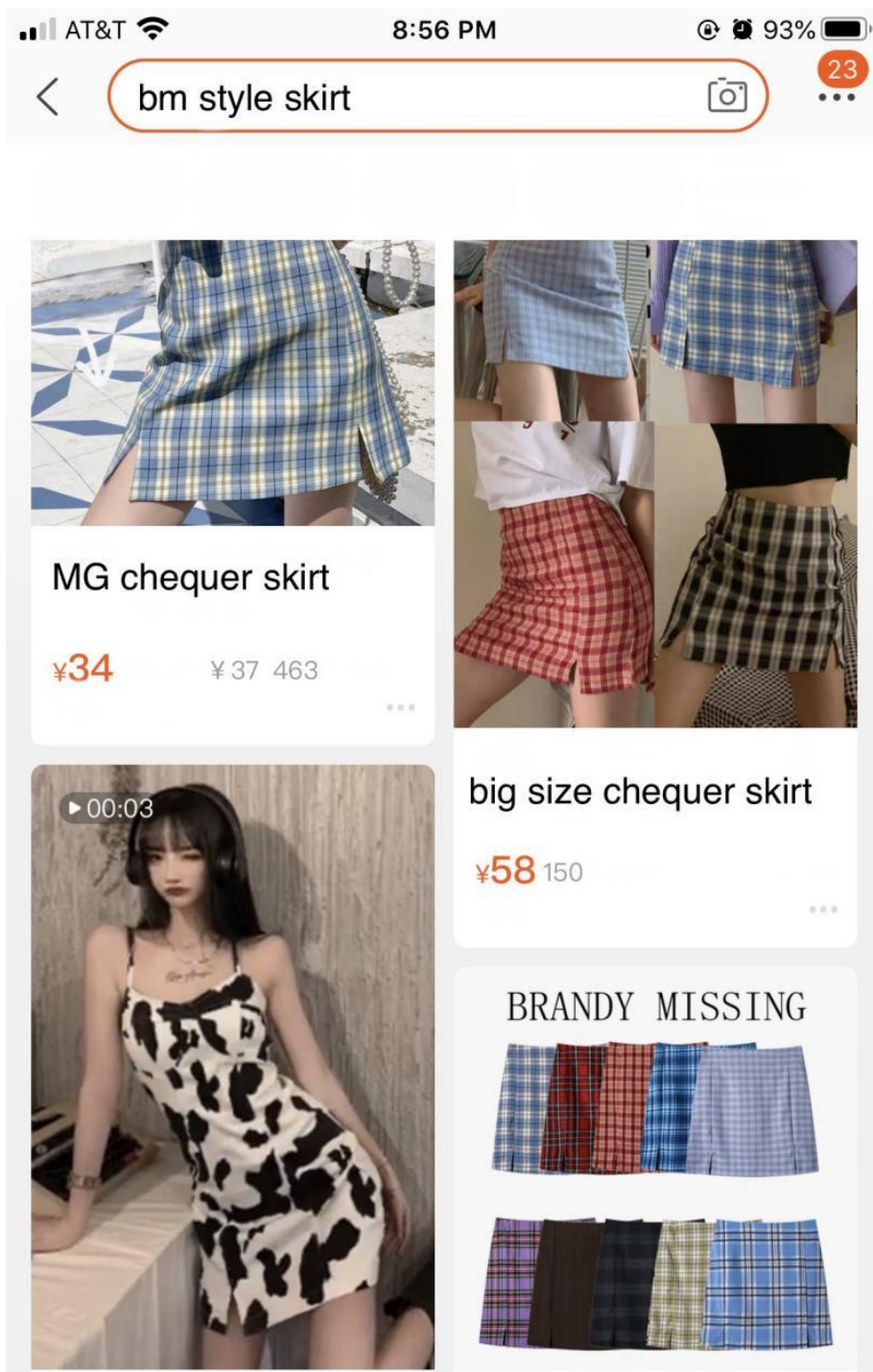

big size chequer skirt

$¥ 58150$

\section{BRANDY MISSING}
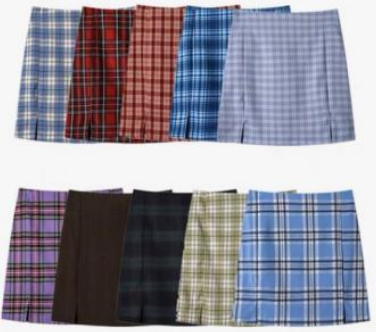

2021 trendy skirt

Brandy Missing skirt

$¥ 3976$

$¥ 58175$

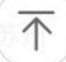

Figure 2 Counterfeit Brandy Melville Products on Taobao

\section{CELEBRITY CHARM}

Advertisements exist in people's everyday lives on social media, TV, billboards, posters on the streets, or even plastic milk tea bottles. Many people find these advertisements tedious and annoying, but this could be changed if their favorite celebrity is promoting that product. Companies know that people worship their favorite idols and oftentimes take to heart what they say, so many advertisers apply this psychological mindset to appeal to their consumers.

For Brandy Melville, celebrity charm is also used on their targeted audience -- young, beautiful girls -- through one of the most popular apps that their target audience uses in China: Weibo.

\subsection{Promotion Through Celebrities}

Ouyang Nana is one of China's youngest, most successful celebrities with over 20 million followers on Weibo, a Chinese equivalent of Instagram. Brandy Melville is very selective in choosing Ouyang Nana to promote its products because of the following factors:

- Brandy Melville's target audience is teenage girls, and Ouyang Nana is also a teenage girl. Aside from the fact that Ouyang Nana has many young fans that suit BrandyMelville's target audience, Ouyang Nana's age has another important benefit: The fact that the celebrity 
is the same age as BM's target consumers makes it more likely for their target audience to find similarities between Ouyang Nana and themselves because they are of the same age. People will listen to people who are more similar to them, and in this case, Ouyang Nana relates more to these young teenage girls. Additionally, the median Weibo user age is 20.8 years, a very close number to Ouyang Nana's age, according to a demographics analysis of China's Weibo users [3].

- On social media, Ouyang Nana is portrayed to be a very fashionable star, and the fact that she is an actress also implies that her visual appearance is wellmaintained and outstanding. Because Ouyang Nana has a reputation for being beautiful, young, and fashionable, consumers will trust her fashion taste and buy the clothing that she promotes. Consumers tend to believe those who are more professional and knowledgeable.Sometimes, finding the right celebrity to promote a company's brand can save the brand. For example, after an unpopular brand in China, Hailan Zhijia, paid a hot Chinese celebrity named Lin Geng Xin to promote its brand, Hailan Zhijia immediately found that its total revenue increased by an incredible $10 \%$ after Lin Gneg Xin's promotion [14]. Many may find it shocking a single person could wield such power over a company, but it also shows that the effectiveness of using celebrity charm is so great that it could actually save the entire company.

After Ouyang Nana posted selfies of her wearing clothes from Brandy Melville, many of the top comments were positive, expressed admiration, and demonstrated a strong interest in the brand. Most of the time in China, advertisers who use celebrities with a good image to appeal to their target audience receive popularity and positive feedback.

Aside from the fact that celebrity charm is a very efficient strategy in itself, there are particular factors about China's demographics that make these advertisement methods so effective:

China's population exceeds 1.4 billion people, making it the world's most populous country. With so many people in a country that shares the same streaming media and apps, sharing information on widely used platforms such as Weibo, with 523 million users, and WeChat, with 1.15 billion users, is much more effective in China compared to a less populated country [2]. Because of the sheer amount of population that China has, many popular Chinese stars can even make hundreds of millions of yuan per year through sponsorships, more than what celebrities in South Korean K-pop industries and Japanese dramas make [8].

\subsection{Effects of Targeting in Marketing}

Targeting in marketing is the strategy that advertisement companies use to target a specific group of customers within a wide, diversified audience. The group contains specific traits and characteristics that advertisers will target the goal of their products. Companies know that it is extremely difficult to reach the entire audience and a waste of money to advertise to groups that are not interested in their product, therefore, companies will focus on appealing to a smaller, defined group. This effective strategy, however, works on different levels accordingly with different cultures [19]. For Brandy Melville, targeting is their main strategy used to gain popularity. In fact, BM's use of celebrity charm targets a very specific audience: young teenage girls who look up to their idols. Targeting in marketing can appear in many different forms in business and appeal to people with similar traits such as culture, language, age, and gender.

For example, targeting in marketing in the US usually consists of very specific and small groups because the US is very diverse. However, this strategy appeals to larger crowds in China (not just because of China's bigger population), but also because of China's lack of diversity compared to the West, and its history of uniformity. The Chinese lived under one written language and one culture for the past 2,300 years, making it a much more unified country compared to the West, where more diversity such as race, religion, and language exists [10]. For advertisers, this immediately eliminates their need to advertise in different languages or explain cultural gaps because the majority of the Chinese share the same culture. China faces fewer language barriers and $90 \%$ of the Chinese are of the same Han descent; in the US, $60.1 \%$ are White, $19 \%$ Hispanic or Latino, $13 \%$ percent are African Americans, etc...[15]. Henceforth, China's lack of diversification makes it much easier and more profitable for advertising companies to target. Indeed, a more specific audience is easier to target rather than a diverse audience with ranging opinions and attitudes.

Although many of Brandy Melville's product promotion methods ended up in failure, there are some very insightful and effective strategies that $\mathrm{BM}$ used to increase its popularity in China. However, for a clothing company like Brandy Melville, consumer interest and need should be taken to greater account.

\section{CONCLUSIONS AND RECOMENDATIONS}

1. Attach great importance to the social responsibility behind public propaganda. Chinese customers attach great importance to the social influence of a brand. To enter a new market (like the Chinese market) and establish a good reputation in the market for a long time, companies need to pay attention to the positive guidance to society in the process of product publicity.

2. Show concepts that focus on diversity from gender, race, and beauty standard, and consider the demand from 
different groups of consumers. This helps satisfy more consumers and broaden companies' target consumers.

3. Balance the level of product scarcity. Counterfeiting is pervasive in China. When the good itself is not too hard to produce (like in Brandy Melville's case) and is not a luxury, try not to make consumers pay efforts in getting it. Counterfeit goods can be easily found for this type of product, so consumers are likely to buy a counterfeit one instead of an original one.

4. Increase the brand's overall diversity -- Whether this diversity refers to the designs, styles, colors, or intended audience. Brands should have variation because it attracts a larger and more diverse crowd. In BM's case, its clothing styles and sizes may not be suitable for the vast majority because BM has a very narrow and specific group of targeted customers, therefore BM's inflexibility and reluctance to change is what decreases the public's demand for BM.

\section{REFERENCES}

[1] BradyGrace. (2020, 14$)$. At Brandy Melville, one size does not fit all, but small. U-HIGH MIDWAY, page 13. China Population (Live). (n.d.). Worldometer. Retrieved from https://www.worldometers.info/worldpopulation/chinapopulation/\#: :text=China $\% 202020 \% 20$ population $\% 20$ is $\% 20$ estimated,(and\%20dependencies)\%20by $\% 20$ population.

[2] DeGennaro, T. (2020, June 30). 10 Most Popular Social Media Sites in China (2020 Updated). Dragon Social. Retrieved November 19, 2020, from https://www.dragonsocial.net/blog/social-media-inchina/

[3] Demographics. (2015, January 27). China Internet Watch. Retrieved from https://www.chinainternetwatch.com/tag/demograp hics/\#: :text=10686\%20university $\% 20$ Weibo $\% 20 u$ sers $\% 20$ were,Weibo $\% 20$ most $\% 2 C \% 20$ with $\% 2023$. $98 \% 25$.

[4] Drizzie. (2020, 4 29). Why Is BM So Hot in China? . Retrieved from LADYMAX: http://news.ladymax.cn/202004/29-35350.html

[5] Goetz, T., Ehret, C., Jullien, S., \& Hall, N. C. (2006). Is the grass always greener on the other side? Social comparisons of subjective well-being. The Journal of Positive Psychology, 1(4), 173-186.

[6] Goodman, L. (2017, 5 19). An Unattainable Ideal: The Struggle for Beauty in China. Retrieved from Foreign Accent: https://medium.com/foreignaccent/an-unattainable-ideal-the-struggle-forbeauty-in-china-3086eb9ba71a
[7] Hamilton, R., Thompson, D., Bone, S., Chaplin, L. N., Griskevicius, V., Goldsmith, K., ... \& Piff, P. (2019). The effects of scarcity on consumer decision journeys. Journal of the Academy of Marketing Science, 47(3), 532

[8] Han, Z. (2019, February 14). Chinese Stars among Highest-earning Worldwide. Global Times. Retrieved from https://www.globaltimes.cn/content/1138915.shtml

[9] Huang, Y. (2004, December 10). Counterfeit Valentino Products. Sina. Retrieved from http://news.sina.com.cn/s/2004-1210/08484484272s.shtml

[10] Li, F. (2018, February 14). China vs. America Uniformity vs. Diversity. Ecointersect. Retrieved from

https://econintersect.com/pages/contributors/contri butor.php?post $=201802140115$

[11] Lin, Yi-Chieh Jessica. Fake stuff: China and the rise of counterfeit goods. Routledge, 2011.

[12] Martin, N. (2018). One Size Fits (Not) All. THE JUNIOR VOICE, 22.

[13] McBride, Caitlin \& Costello, Nancy \& Ambwani, Suman \& Wilhite, Breanne \& Austin, S. Bryn (2019) Digital Manipulation of Images of Models' Appearance in Advertising: Strategies for Action Through Law and Corporate Social Responsibility Incentives to Protect Public Health. American Journal of Law \& Medicine. Vol. 45 Issue 1, p7-31. $25 \mathrm{p}$.

[14] Ning, F. H. (2018, July 7). Ling Geng Xin saved Hailan Zhijia, Its Revenue Increased by $110 \%$. PE Daily. https://m.pedaily.cn/new/433729

[15] Quick Facts United States. (n.d.). United States Census Bureau. Retrieved from https://www.census.gov/quickfacts/fact/table/US/P ST045219?

[16] Schneider, K. (2019, 10 3). The Secret Shame of Wearing Brandy Melville. Retrieved from THE CUT: https://www.thecut.com/2019/10/the-secretshame-of-wearing-brandy-melville.html

[17] Schwartzman, S., \& Arnsberger, A. (2018, 6) Brandy Melville amplifies unrealistic body standards. Retrieved from THE BEACON: https://thewilsonbeacon.com/12243/opinions/brand y-melville-amplifies-unrealistic-body-standards/

[18] Stock, A., \& Balachander, S. (2005). The Making of a "Hot Product": A Signaling Explanation of Marketers' Scarcity Strategy. Management Science,51(8), 1181-1192. 
[19] Yesbeck, J. (n.d.). The Importance of Targeting in Marketing (And How to Include It in Your Strategy). Alexa. Retrieved from https://blog.alexa.com/targeting-in-marketing/

[20] Yu, M., Ahn, H., \& Kapuscinski, R. (2015).
Rationing Capacity in Advance Selling to Signal Quality. Manag. Sci., 61, 560-577.

[21] ZhangLei. (2018, 10 10). To be thin but not healthy - The body-image dilemma may affect health among female university students in China. 